\title{
Clonal haematopoiesis and clonal selection in wine
}

\author{
Shaun R. McCann $\mathbb{1}^{1}$
}

Received: 17 June 2020 / Revised: 23 June 2020 / Accepted: 30 June 2020 / Published online: 8 July 2020

(c) Springer Nature Limited 2020

'It has become quite a common proverb that in wine there is truth'

Naturalis Historia. Book X1V, sec 141, Pliny the elder (AD 23-79), author and natural philosopher (Fig. 1).

A clone is a group of identical cells that share a common ancestry, meaning they are derived from the same cell. I suppose the best known 'clonal' disease in haematology is multiple myeloma (MM). Although it has been recognised since ancient times the first well-documented case was reported in 1844 by Samuel Solly [1]. The most commonly recognised case is that of Thomas Alexander McBean, a tradesman from London in 1850 who excreted a large amount of protein that was described by Henry Bence Jones in the middle of the 19th century [2]. Bence Jones described a protein in the urine that became opaque when boiled. Although many physicians use the term 'Bence Jones' proteinuria, I doubt if many physicians boil the patient's urine at the bedside or in the clinical laboratory, but more than likely refer the urine specimen for electrophoresis/ immuno-electrophoresis in the immunology or biochemistry laboratory, depending on which department had won the power struggle. The recognition of plasma cells and their product, a monoclonal protein, remain the bedrock of this disease but thankfully its prognosis has been radically altered recently with the advent of new therapeutic interventions, including immunomodulatory drugs, proteosome inhibitors and autologous haemopoietic cell transplantation. The aetiology in most cases remains obscure, but has been linked to benzene and dioxins (such as those found in Agent Orange, an exfoliating agent, used by the Americans in

Shaun R. McCann

shaunrmccann@gmail.com

1 Haematology, Emeritus, Trinity College Dublin, Dublin, Ireland
Vietnam but prior to that, by the British in Malaya/ Malaysia) [3].

Although clonal haematopoiesis has been discussed for over 25 years [4, 5], a number of haematological malignancies are now known to be associated with it, including AML (Acute Myeloid Leukaemia), MDS (Myelodysplasia), MM and CLL (Chronic Lymphocytic Leukaemia), and perhaps some solid tumours. Clonal evolution [6] and marked cellular genetic changes, which are evident at the time of disease relapse, are evident in the above diseases. Clonal evolution, the changing of the phenotype of cancer cells over time, makes the detection of measurable residual disease more difficult but not impossible. Landau and colleagues also claim that branching rather than linear is the predominant pattern of clonal evolution, and that newer technologies might define the dichotomy of driver versus passenger mutations. Of course, clonality and malignancy are not the same thing as most of us would not classify paroxysmal nocturnal haemoglobinuria as malignant although it is clonal.

More recently, a new terminology has entered the lexicon, CHIP (clonal haematopoiesis of indeterminate potential), which is somewhat akin to MGUS (monoclonal gammopathy of uncertain significance) that has been used for many years. Both increase in prevalence with increasing age (as does skewing of $\mathrm{X}$ inactivation) and exhibit a definite, but very small predisposition to malignancy ( $1 \%$ per year over the age of 70 years). It is important to remember that CHIP can occur with normal blood counts, or with pancytopenia and likewise MGUS can be found in asymptomatic elderly people.

Are clones important to wine makers? Yes. In vegetative reproduction (asexual), in which a cutting is taken from a single parent plant and grafted onto existing rootstock, the new vines, being clones of the mother vine they were cut from, exhibit similar characteristics to those mother vines. Clones are important because clones of the same grape variety may differ in terms of berry size, acidity, tannin sugar levels and colour intensity among other characteristics. According to Jancis Robinson [7], 
the Germans were among the first to recognise the importance of clonal selection. However, many clones may mutate over time. Pinot Noir clone B777 (Fig. 2) is well known, but is sometimes planted with UCD5 and B115. Pinot Noir (Nero in Italy) is an ancient grape and was widely cultivated by the monks in Burgundy since the seventh century. This was overturned during the French Revolution and lands were subsequently confiscated and redistributed to civilian owners by Napoleon 1st. Partly because of its history, it mutates frequently and in France alone there are over 50 clones of Pinot Noir. The fre-

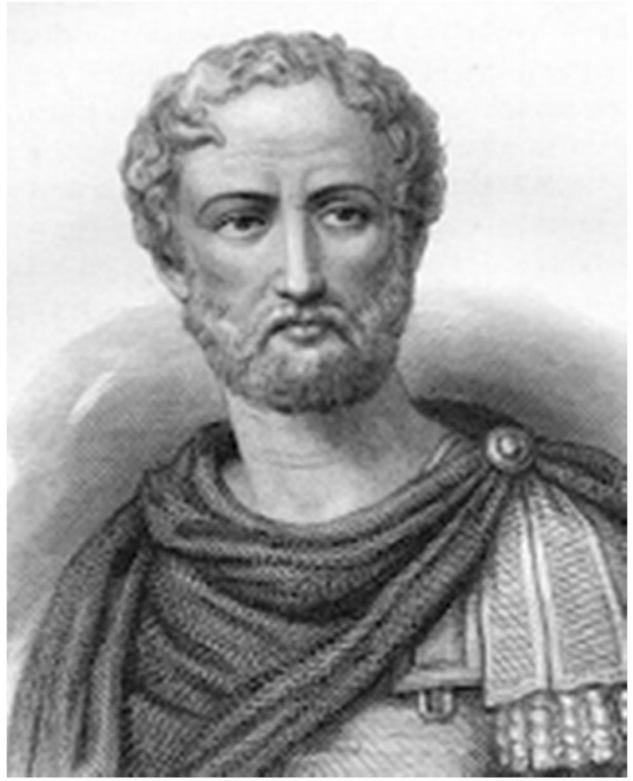

Fig. 1 Pliny the Elder. Pliny was a Roman philosopher who wrote a lot about wine.

Fig. 2 Pinot Noir B777. This clone is widely planted often in conjunction with other clones of Pinot Noir grapes. quency of viral diseases led to the widespread use of clonal selection in Burgundy during the 1970s [8]. Cabernet Sauvignon, so beloved to many of us, apparently underwent spontaneous crossing between Cabernet Franc and Sauvignon Blanc in France in the seventeenth century.

As my friend Leon Femfert said to me when asked about clonal selection: 'You'll probably get different answers from different vineyards'. Many wine makers I spoke to used what is called Massal selection (Selection Massale in France) to increase individuality and the uniqueness of their wine. As Barbara Widmer told me: 'We started with the massal selection 10 years ago; since 2017 we use for each estate and each variety only the massal selection'. However, as winemaker Piero Lanzo from Fattoria Poggerino outside Radda said: 'I believe that using clonal selection allows a more even ripening and a greater guarantee of vines free of fungus. It is exactly the combination of various clones that creates complexity in the wines. However, in the end, whether it be clonal or mass selection the most important factor in the quality of wine is, above all, terroir, the combination of the soil and the microclimate in which the vineyard is planted'. And Pamela Lenzi of Petroio said: 'Many vineyards in Chianti Classico have gone to Selezione Masalle'.

So, although clonal haematopoiesis increases with age wine makers use some form of clonal selection but the terroir is important.

Acknowledgements The author thanks wine makers, Leon Femfert, Nittardi, Barbara Widmer, La Brancaia, Piero Lanza, Fattoria Poggerino and Pamela Lenzi, Petroio for helpful advice.

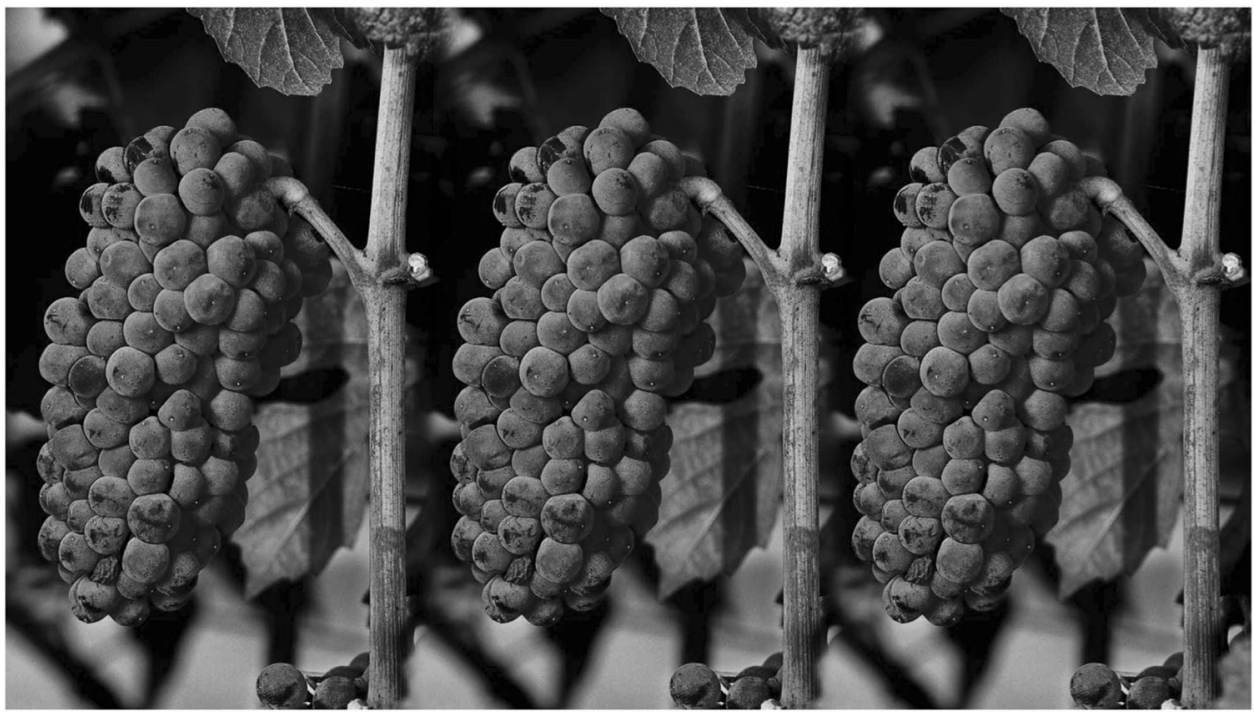




\section{Compliance with ethical standards}

Conflict of interest The authors declare that they have no conflict of interest.

Publisher's note Springer Nature remains neutral with regard to jurisdictional claims in published maps and institutional affiliations.

\section{References}

1. Solly S. Remarks on the pathology of mollities ossium. With cases. J R Soc Med. 1844;27:435-61.

2. Bence Jones H. Papers on chemical pathology. Lancet. 1847;50: 88-92.
3. Landgren O, Shim YK, Michalek J, Costello R, Burton D, Ketchum N. et al. Agent orange exposure and monoclonal gammopathy of undetermined significance: an operation ranch hand veteran cohort study. JAMA Oncol. 2015;1:1061-8. https://doi.org/10.1001/jama oncol.2015.2938.

4. Linder D, Gartler SM. Glucose-6-phosphate dehydrogenase mosaicism: utilization as a cell marker in the study of leiomyomas. Science. 1965;150:67-9.

5. Fialkow PJ. The origin and development of human tumours studied with cell markers. N. Engl J Med. 1974;291:26-35.

6. Landau DA, Carter SL, Getz G, Wu CJ. Clonal evolution in hematological malignancies and therapeutic implications. Leukemia. 2014;28:34-43.

7. Robinson J. Vines, grapes and wines. London: Octopus Publishing group; 1992.

8. Robinson J, Harding J. The Oxford companion to wine. 4th edn. Oxford: Oxford University Press; 2015. 